\title{
Milnacipran: a unique antidepressant?
}

\author{
This article was published in the following Dove Press journal: \\ Neuropsychiatric Disease and Treatment \\ 30 August 2010 \\ Number of times this article has been viewed
}

\author{
Siegfried Kasper \\ Gerald Pail \\ Department of Psychiatry \\ and Psychotherapy, Medical \\ University of Vienna, Austria
}

Correspondence: Siegfried Kasper Department of Psychiatry and Psychotherapy, Medical University of Vienna, AKH, Währinger Gürtel 18-20, A-1090 Wien, Austria $\mathrm{Tel}+43 \quad$ I40 4003568

Fax +43 I40 4003099

Email sci-biolpsy@meduniwien.ac.at
Abstract: Tricyclic antidepressants (TCAs) are among the most effective antidepressants available, although their poor tolerance at usual recommended doses and toxicity in overdose make them difficult to use. While selective serotonin reuptake inhibitors (SSRIs) are better tolerated than TCAs, they have their own specific problems, such as the aggravation of sexual dysfunction, interaction with coadministered drugs, and for many, a discontinuation syndrome. In addition, some of them appear to be less effective than TCAs in more severely depressed patients. Increasing evidence of the importance of norepinephrine in the etiology of depression has led to the development of a new generation of antidepressants, the serotonin and norepinephrine reuptake inhibitors (SNRIs). Milnacipran, one of the pioneer SNRIs, was designed from theoretic considerations to be more effective than SSRIs and better tolerated than TCAs, and with a simple pharmacokinetic profile. Milnacipran has the most balanced potency ratio for reuptake inhibition of the two neurotransmitters compared with other SNRIs (1:1.6 for milnacipran, 1:10 for duloxetine, and 1:30 for venlafaxine), and in some studies milnacipran has been shown to inhibit norepinephrine uptake with greater potency than serotonin (2.2:1). Clinical studies have shown that milnacipran has efficacy comparable with the TCAs and is superior to SSRIs in severe depression. In addition, milnacipran is well tolerated, with a low potential for pharmacokinetic drug-drug interactions. Milnacipran is a first-line therapy suitable for most depressed patients. It is frequently successful when other treatments fail for reasons of efficacy or tolerability.

Keywords: milnacipran, SNRI, antidepressant efficacy, tolerability

\section{Introduction}

Depression is characterized by the presence of two core symptoms, depressed mood and anhedonia (decreased pleasure or interest). It is also accompanied, however, by a plethora of other signs and symptoms, such as changes in appetite and sleeping, fatigue and loss of energy, psychomotor agitation or retardation, feelings of worthlessness or inappropriate guilt, diminished ability to think or concentrate, and recurrent thoughts of death or suicide. ${ }^{1}$ A relationship exists between the monoamine neurotransmitters in the brain, norepinephrine (NE) and serotonin (5-hydroxytryptamine, 5-HT) and the symptoms of major depressive disorder (Figure 1). ${ }^{2}$ Specific symptoms are thought to be associated with the increase or decrease of specific monoamines, implying the involvement of specific neurochemical mechanisms.

Virtually all antidepressants increase the synaptic concentrations of 5-HT and/or NE by blocking the reuptake of one or both of these neurotransmitters. The archetypal tricyclic antidepressants (TCAs) block NE and 5-HT transporters to a varying extent depending on the particular compound. ${ }^{3}$ Although they are among the most effective 


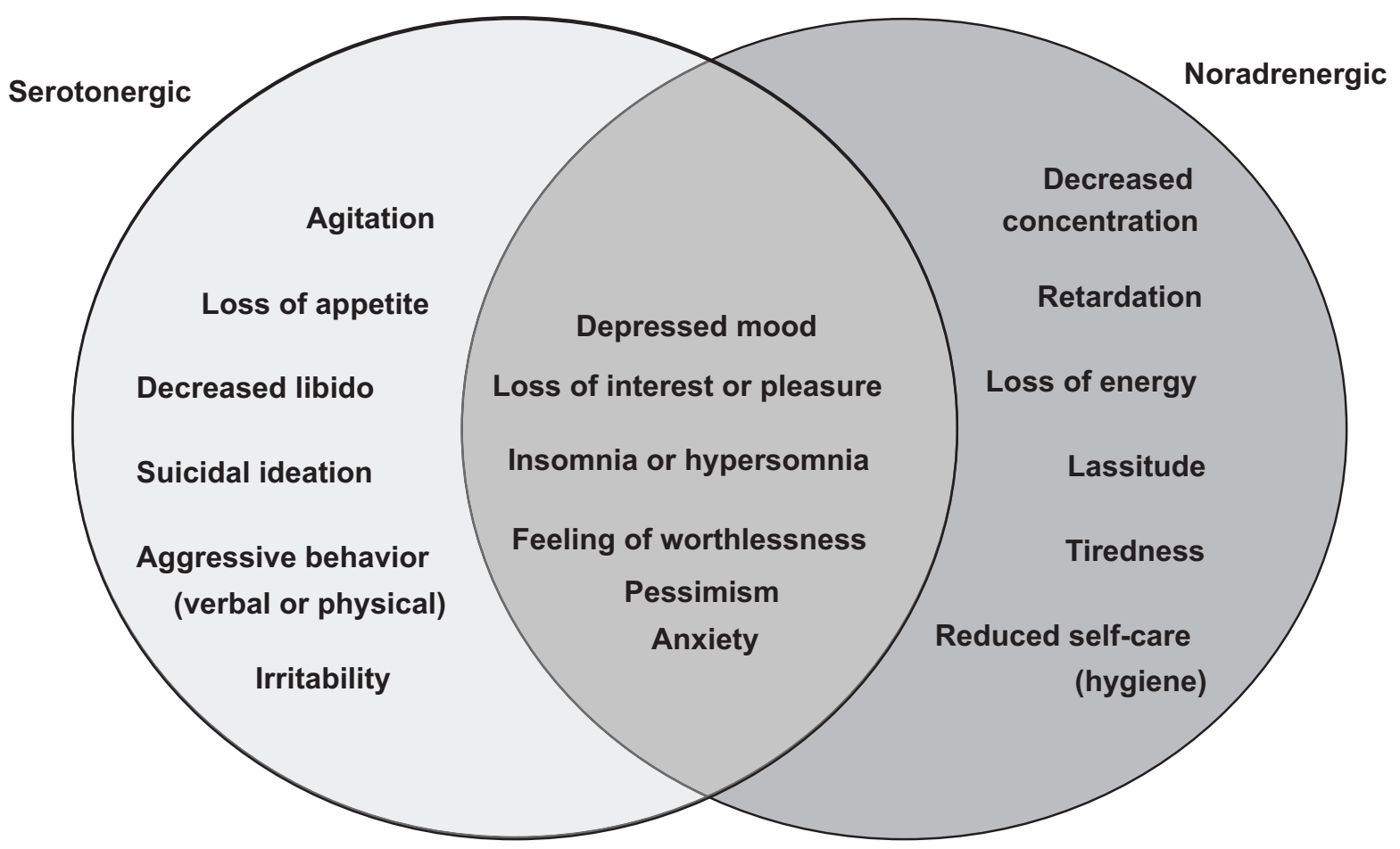

Figure I Relation between neurotransmitters and symptoms of depression. Adapted from Nutt. ${ }^{2}$

antidepressants available ${ }^{4}$ their poor tolerance and toxicity in overdose due to the involvement of other neurotransmitter systems make them difficult to use at effective doses. ${ }^{5}$ The principal side effects of the TCAs are considered to be due essentially to their relatively high affinity for $\alpha_{1}$-adrenergic receptors, $\mathrm{H}_{1}$-histamine receptors, and muscarinic cholinergic receptors. ${ }^{6}$ The selective serotonin reuptake inhibitors (SSRIs) which inhibit selectively the single neurotransmitter, 5-HT, are effective antidepressants. Although they have no affinity for $\alpha_{1}$-adrenergic receptors, $\mathrm{H}_{1}$-histamine receptors, and muscarinic cholinergic receptors, and are better tolerated than TCAs, ${ }^{6}$ they have their own specific problems, such as aggravation of sexual dysfunction, interaction with coadministered drugs and, for many, a discontinuation syndrome. ${ }^{7}$ In addition, some of them appear to be less effective than TCAs, with a number needed to treat for TCAs of about four compared with six for SSRIs in primary care. ${ }^{8}$ The difference is most pronounced in more severely depressed patients. ${ }^{9}$

In general, antidepressants achieve a response ( $\geq 50 \%$ reduction in baseline depression score) in less than $70 \%$ of patients and remission (a complete absence of depressive symptoms) in less than $50 \%$. Increasing evidence of the importance of NE in the etiology of depression ${ }^{10}$ and the idea that "two actions are better than one" have led to the development of a new class of compounds that block the reuptake of both 5-HT and NE without the nonspecific, side effect-inducing receptor interactions of TCAs. This class, the serotonin (5-HT) and NE reuptake inhibitors (SNRIs) comprises venlafaxine (and its active metabolite, desvenlafaxine), duloxetine, and milnacipran. ${ }^{11}$

By definition, the SNRIs inhibit both 5-HT and NE transporters. There is, however, considerable difference in their selectivity for the two transporters (Table 1 and Figure 2). Venlafaxine has a much greater affinity for the 5-HT transporter than for the NE transporter. At low doses, it probably inhibits almost exclusively the 5-HT transporter, acting like a SSRI, with significant NE reuptake inhibition only occurring at higher doses. Duloxetine has a more balanced affinity, but is still more selective for the 5-HT transporter. Milnacipran is the most balanced SNRI, and some studies have even found it to be slightly more

Table I Inhibition of binding to human monoamine transporters in vitro

\begin{tabular}{lllll}
\hline Potency ratio & Ki $(\mathbf{n M})$ & & Selectivity \\
\cline { 2 - 3 } & $\mathbf{5 - H T}$ & NE & NE/5-HT \\
\hline Milnacipran & 123 & 200 & $1 / 1.6$ \\
Duloxetine & 0.8 & 7.5 & $1 / 9$ \\
Venlafaxine & 82 & 2483 & $1 / 30$ \\
Desvenlafaxine & 40 & 558 & $1 / 14$ \\
\hline
\end{tabular}

Milnacipran, duloxetine and venlafaxine data from Koch et $\mathrm{a}^{55}$ and desvenlafaxine data from Deecher et al. ${ }^{56}$

Abbreviations: NE, norepinephrine; 5-HT, 5-hydroxytryptamine (serotonin). 


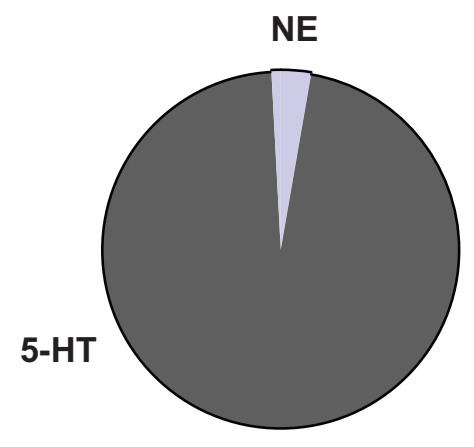

Venlafaxine

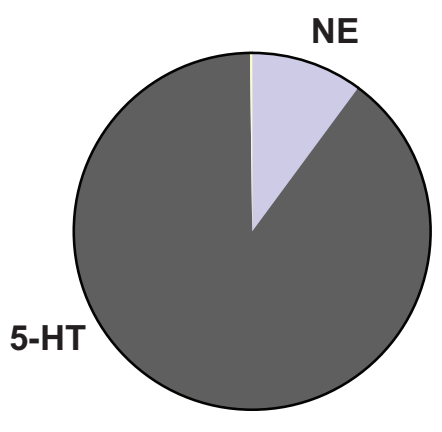

Duloxetine

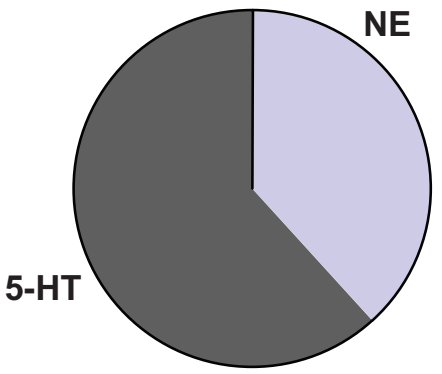

Milnacipran

Figure 2 Selectivity of different serotonin and norepinephrine reuptake inhibitors for the monoamine transporters. The segments represent the selectivity for the human norepinephine and serotonin $(5-\mathrm{HT})$ transporters calculated according to data from Koch et al..$^{55}$

effective for the NE transporter ${ }^{12}$ compared with the 5-HT transporter.

There is frequently confusion between the terms "selectivity" and "potency", which refer to two different entities. Potency reflects the concentration of the antidepressant inhibiting $50 \%$ of uptake or binding to the transporter, depending on the technique used. Thus from Table 1 it can be seen that duloxetine is 154 times more potent than milnacipran at blocking the binding of 5-HT to the transporter (ie, 154 times more milnacipran is required to obtain the same effect). To block the binding of NE to its transporter, duloxetine is about 27 times more potent than milnacipran. If absorption, metabolism, distribution, brain penetration and distribution, and elimination were identical for the two drugs, it would be necessary to give 154 times more milnacipran than duloxetine to achieve the same effect on 5-HT reuptake and 27 times more milnacipran to have the same effect on NE reuptake. Of course the kinetic parameters vary considerably between these two compounds, and certain parameters are impossible to determine in humans (eg, brain penetration) and hence this calculation remains purely theoretical.

The selectivity of an antidepressant is the ratio of the potency values for NE and 5-HT reuptake inhibition (or inhibition of binding to the transporter). As shown in Table 1, milnacipran has a selectivity close to 1 , duloxetine close to 10 (in favor of 5-HT), and venlafaxine close to 30. Thus, in a dose titration, when milnacipran starts to inhibit 5-HT reuptake, it also starts to inhibit NE reuptake; when it inhibits 5-HT reuptake by 50\%, it also inhibits NE reuptake by approximately $50 \%$, and so on. Increasing the dose does not alter the "nature" of the effect. At all doses it has an equivalent effect on the two neurotransmitters systems. In contrast, a dose titration with venlafaxine will give (eg, at $75 \mathrm{mg}$ ) an initial inhibition of 5-HT reuptake with no inhibition of NE uptake. Only at much higher doses (eg, 200-250 mg) is there any significant inhibition of NE reuptake, but at this dose the inhibition of 5-HT reuptake is already $100 \%$. Thus, titrating venlafaxine changes the "nature" of its effect from a SSRI to a SNRI as the dose is increased. The situation with duloxetine is intermediate between milnacipran and venlafaxine.

There are some indications that the mechanism of milnacipran may be more complex than a simple action at the monoamine transporter, and thus is different from the other SNRIs. A study assessed the effect of milnacipran on the firing activity of dorsal raphe 5-HT neurons and locus coeruleus NE neurons using extracellular unitary recording in rats. ${ }^{13}$ The authors concluded that milnacipran had profound effects on the function of 5-HT and NE neurons, but that the mechanism by which 5-HT neurons regained their normal firing during milnacipran treatment appears to implicate the NE system.

In a more recent study, ${ }^{14}$ duloxetine and venlafaxine were found to increase 5-HT levels in the brainstem and 5-HT terminal areas, whereas milnacipran increased 5-HT levels only in the brainstem. Significant reductions in 5-HT turnover were observed in various forebrain regions, including the hippocampus and hypothalamus, after treatment with duloxetine or venlafaxine, but not after milnacipran. In addition, venlafaxine and duloxetine significantly increased dopamine (DA) levels and decreased DA turnover in the nucleus accumbens, whereas milnacipran only increased DA levels in the medial prefrontal cortex. The authors concluded that the effects of milnacipran were unique because it caused increases in DA in the medial prefrontal cortex and in 5-HT in the midbrain without any changes in monoamine turnover. They suggested that milnacipran might exert its therapeutic effects by activating the dopaminergic system in the medial prefrontal cortex, and that milnacipran was in this respect different from duloxetine and venlafaxine. 


\section{Some notable characteristics of milnacipran}

In addition to its balanced action on the two monoamine transporters, preclinical and clinical studies have shown that milnacipran possesses certain characteristics which are relatively unusual in an antidepressant.

Milnacipran has no active metabolites. Unlike the majority of antidepressants, milnacipran is only metabolized to a very minor extent, with most of the administered drug being excreted in the urine either unchanged or as the inactive glucurono-conjugate. ${ }^{15}$ Whereas most antidepressants interact with cytochrome P450 enzymes as inhibitors, inducers, or substrates ${ }^{16}$ milnacipran has been shown to be essentially devoid of interactions with any cytochrome P450 enzyme. ${ }^{17}$ In addition, milnacipran binds to only a very limited extent (13\%) to serum albumin. ${ }^{15}$ Milnacipran, therefore, has a low risk of pharmacokinetic drug-drug interactions.

Depression is associated with sexual disturbances, including decreased libido, anorgasmia, and erectile problems. Since introduction of the SSRIs, it has become apparent that aggravation of sexual dysfunction is a frequent problem for patients taking these drugs, with some studies reporting rates as high as $75 \% .{ }^{18}$ Sexual dysfunction caused by SSRIs is related to stimulation of $5-\mathrm{HT}_{2}$ and $5-\mathrm{HT}_{3}$ receptors but its origin is complex and probably involves other systems as well. ${ }^{19}$ Venlafaxine ${ }^{20}$ and duloxetine ${ }^{21,22}$ also exacerbate sexual dysfunction at frequencies similar to those seen with SSRIs. A study using the Sexual Function and Enjoyment Questionnaire ${ }^{23}$ showed no aggravation of sexual disturbance with milnacipran, which improved sexual function in parallel with improvement in other symptoms of depression.

Following abrupt discontinuation, most SSRIs, and paroxetine in particular, produce a number of adverse events, including dizziness, nausea, headache, paresthesia, vomiting, irritability, and nightmares. ${ }^{24}$ Venlafaxine and duloxetine produce similar discontinuation emergent adverse events. ${ }^{25,26}$ A post hoc analysis of patients abruptly withdrawn from paroxetine or milnacipran as part of a double-blind comparative study ${ }^{27}$ showed that paroxetine produced significantly more discontinuation emergent adverse events than milnacipran. In addition, the nature of the adverse events differed between the two antidepressants, with patients withdrawn from paroxetine showing the classical symptoms of dizziness, anxiety, and sleep disturbance (insomnia and nightmares), while those withdrawn from milnacipran showed only increased anxiety. However, some discontinuation symptoms have been reported, and good clinical practice and regulatory authorities always recommend gradual discontinuation from any psychotropic drug.
Certain antidepressants are associated with clinically significant weight changes. In particular, some TCAs including amitriptyline, certain SSRIs including paroxetine, and other antidepressants, such as mirtazapine, are frequently associated with significant weight gain. ${ }^{28}$ Data from a wide range of clinical trials ${ }^{29}$ have shown that $82 \%$ of patients taking milnacipran $100 \mathrm{mg}$ /day for 3 months or more have no clinically significant weight change (defined as $>5 \%$ of body weight). Of the remainder, $10 \%$ had clinically significant weight loss, while $8 \%$ had clinically significant weight gain.

\section{Comparison of milnacipran with TCAs and SSRIs}

Seven randomized, double-blind trials with similar designs have compared the efficacy and tolerability of milnacipran and TCAs in patients with major depression. At a dose of $100 \mathrm{mg} /$ day the response rate with milnacipran (64\%) was comparable with that of the TCAs (67\%). In contrast with the TCAs, milnacipran was very well tolerated by patients. ${ }^{30}$

A meta-analysis of studies comparing milnacipran at $100 \mathrm{mg} /$ day with the SSRIs, fluvoxamine $(200 \mathrm{mg} /$ day $)$ and fluoxetine $(20 \mathrm{mg} /$ day $)$, in moderately to severely depressed hospitalized patients, ${ }^{31}$ reported significantly more responders $(64 \%)$ with milnacipran than with the two SSRIs $(50 \%$, $P<0.01)$ and a significantly higher remission rate $(38.7 \%$ versus $27.6 \%, P<0.04)$. Another study, published subsequent to this meta-analysis, compared milnacipran with paroxetine $20 \mathrm{mg} /$ day in less severely depressed outpatients, and reported similar remission rates for the two antidepressants. ${ }^{32}$

Table 2 summarizes two studies, each comparing milnacipran with a SSRI, one in moderately to severely depressed hospitalized patients, ${ }^{33}$ and the other in less severely depressed outpatients. ${ }^{34}$ The two studies, which investigated two different SSRIs in different treatment settings, cannot be

Table 2 Efficacy of milnacipran compared with SSRIs: comparison of two studies in mild-to-moderate and severe depression

\begin{tabular}{|c|c|c|c|c|}
\hline & \multicolumn{4}{|c|}{ Mean MADRS scores } \\
\hline & \multicolumn{2}{|c|}{ Mild-moderate 32} & \multicolumn{2}{|c|}{ Severe $^{33}$} \\
\hline & Miln & SSRI' & Miln & $\mathbf{S S R I}^{2}$ \\
\hline Baseline & 28.9 & 29.6 & 37.1 & 35.5 \\
\hline Endpoint & $13.6^{\S}$ & $12.8^{\S}$ & $12.9 \$ * *$ & $18.1^{\S}$ \\
\hline$\Delta$ score (endpoint - baseline) & 15.3 & 16.8 & $24.2 *$ & 17.4 \\
\hline
\end{tabular}

Notes: 'paroxetine $20 \mathrm{mg} / \mathrm{day}$; ${ }^{2}$ fluvoxamine $200 \mathrm{mg} /$ day; ${ }^{\$} \mathrm{P}<0.05$ compared with the corresponding baseline value; $* P<0.05$ compared with the corresponding value for the SSRI group.

Abbreviations: MADRS, montgomery asberg depression rating scale; miln, milnacipran $100 \mathrm{mg} /$ day; SSRls, selective serotonin reuptake inhibitors. 
compared directly. Nevertheless, it is interesting to note that milnacipran was associated with significant improvement in both studies. In contrast, the SSRIs led to an improvement comparable with that of milnacipran in the study of less severely depressed patients, but not in the study of patients with severe depression. Unlike milnacipran, SSRI treatment did not achieve the additional reduction in depression score needed in the severely depressed patients to reach response. Clearly this analysis is only indicative and the severity of depression was not the only factor that differed between the studies. Nevertheless, the results are compatible with other data $^{34}$ suggesting that SSRIs may have a limited capacity for improving depressive symptoms, which becomes more evident in more severely depressed patients.

In the study comparing milnacipran with paroxetine $20 \mathrm{mg} /$ day, ${ }^{32}$ the overall efficacy of the two antidepressants was similar. However, milnacipran was significantly better than paroxetine in the subgroup of patients scoring maximally at baseline on the retardation-slowness of thought and speech, impaired ability to concentrate, and decreased motor activity factor (item 8) on the Hamilton Depression Rating Scale (HDRS, Figure 3). This is compatible with the finding that reduced noradrenergic neuronal tone is related to psychomotor retardation. ${ }^{35}$ Furthermore, the selective NE reuptake inhibitor has been shown to improve psychomotor retardation systematically, even when other symptoms were not improved. ${ }^{36}$ These data suggest that depressed patients with marked psychomotor retardation may benefit particularly from treatment with milnacipran.

In studies comparing milnacipran with SSRIs, both compounds are generally well tolerated. The most frequent adverse event with both milnacipran and SSRIs is nausea, although this occurred less frequently with milnacipran. ${ }^{31} \mathrm{As}$ would be expected, adverse effects that are probably related to noradrenergic stimulation, such as dry mouth, sweating, and constipation, occur more frequently with milnacipran than with SSRIs, although the differences are not as large as might be expected. ${ }^{31}$

A meta-analysis of all published studies comparing milnacipran with SSRIs ${ }^{37}$ concluded that patients on milnacipran had the same probability of obtaining a clinical response as those on SSRIs. As with many meta-analyses, however, this global analysis grouped certain atypical studies which should have been analyzed separately. For example, one study ${ }^{38}$ comparing milnacipran with fluoxetine used once-daily dosing for both of the antidepressants. In view

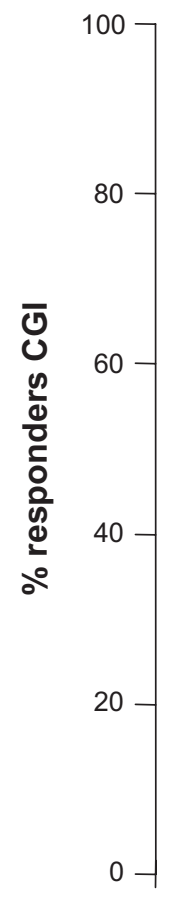

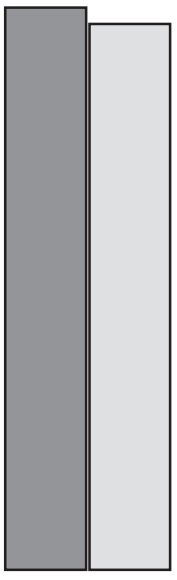

All

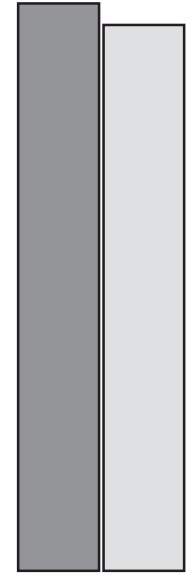

0 or 1

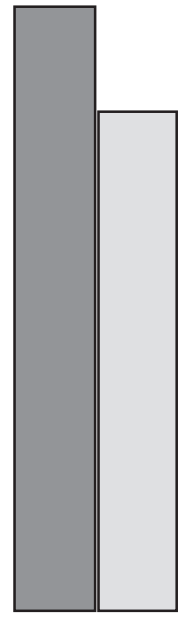

2

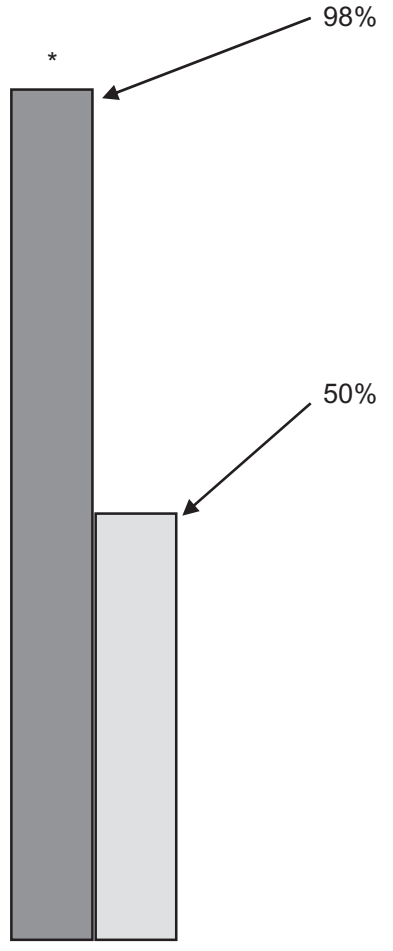

3 or 4

\section{Retardation} score

Figure 3 Antidepressant response and psychomotor retardation. Retardation score was the score of item 8 on the Hamilton Depression Rating Scale (slowness of thought and speech, impaired ability to concentrate, decreased motor activity). Dark grey columns = milnacipran; light grey columns = paroxetine. Figure drawn from data in Sechter et al. $^{32} * p<0.05$ 
of the half-life of milnacipran (7-8 hours) this protocol was inappropriate given that twice daily dosing of milnacipran is recommended. In two studies, ${ }^{39,40}$ each comparing two doses of milnacipran with a single dose of a SSRI, the metaanalysis inappropriately compared each dose of milnacipran with the SSRI, using the single SSRI group twice, thus giving excessive importance to the SSRI groups. Most importantly, however, the analysis combined, without distinction, data from a study in severely depressed hospitalized patients ${ }^{33}$ (baseline HDRS > 32) with data from studies in mildly depressed outpatients ${ }^{32,41}$ (baseline HDRS $<24$ ).

Another analysis of studies comparing milnacipran with SSRIs $^{42}$ concluded that, on the basis of all available evidence, milnacipran, like duloxetine and mirtazapine, had "probable superior efficacy" compared with SSRIs.

\section{Comparison of milnacipran with other SNRIs}

With the exception of the study described in this supplement ${ }^{43}$ which showed equivalent efficacy of milnacipran and venlafaxine at high doses, no studies comparing milnacipran with other SNRIs have been carried out. However, all three SNRIs have been compared with SSRIs, and comparisons of venlafaxine with SSRIs and milnacipran with SSRIs have been subjected to meta-analyses which have been juxtaposed for comparison. ${ }^{11}$ A similar level of efficacy for the SSRIs was seen across all of the studies. Milnacipran, as well as venlafaxine, produced remission rates about $10 \%$ higher than those of the SSRIs. ${ }^{11}$ More recently a meta-analysis of 93 trials comparing a dual-action antidepressant (venlafaxine, milnacipran, duloxetine, mirtazapine, mianserin, or moclobemide) with one or more SSRIs has been published. ${ }^{44}$ This analysis, involving over 17,000 patients, confirms the overall superiority of the dual-action antidepressants compared with the SSRIs (Figure 4). In addition, this meta-analysis shows a similar level of efficacy for all of the dual-action antidepressants, with the exception of duloxetine which, in this analysis, was less effective than the other dual-acting agents. Thus, it would seem reasonable to conclude that there is a comparable level of antidepressant efficacy for milnacipran and venlafaxine and probably duloxetine, although further data is required for the latter.

Similarly, in the absence of direct comparative studies between the SNRIs it is not possible to draw any firm conclusions on comparative tolerability. However, in the various studies comparing an SNRI with SSRIs, the side effect profiles of all three SNRIs show qualitative differences in comparison with those of the SSRIs. The most common adverse effects with the SSRIs are nausea, vertigo/dizziness, dry mouth, and insomnia. Only dry mouth appears to be

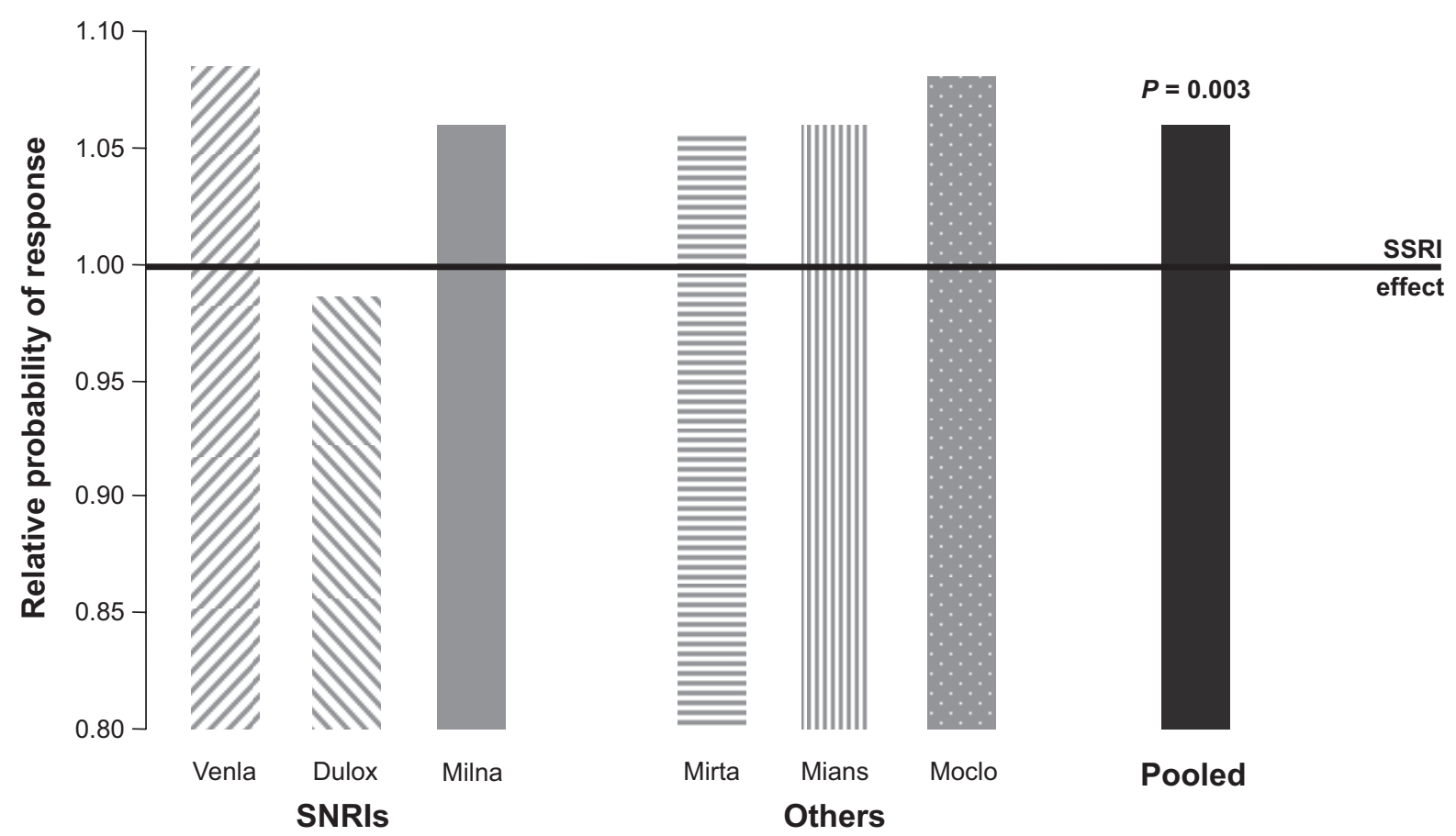

Figure 4 Meta-analysis of 93 studies comparing dual action antidepressants and selective serotonin reuptake inhibitorsinvolving 17,036 patients. ${ }^{37}$ Columns show the relative probability of response compared with selective serotonin reuptake inhibitors. Figure drawn from data in Papakostas et al. ${ }^{44}$

Abbreviations: venla, venlafaxine; dulox, duloxetine; milna, milnacipran; mirta, mirtazapine; mians, mianserin; moclo, moclobemide. 
systematically more common with SNRIs than with SSRIs. The dry mouth experienced with SNRIs is of noradrenergic origin and is analogous to that encountered during stress. The overall frequency of adverse events with milnacipran appears to be less than for venlafaxine and duloxetine. ${ }^{11}$ However, direct head-to-head comparisons are needed before any firm conclusions can be drawn.

Fatalities have been reported due to overdose of venlafaxine alone or in combination with other compounds, ${ }^{45,46}$ often following serotonin syndrome. Fatal toxicity index (deaths caused by a drug/million prescriptions) is a very crude measure of drug toxicity and should be interpreted with caution. Nevertheless, fatal toxicity studies from England, Scotland, and Wales have provided some interesting data. Deaths due to acute poisoning by a single antidepressant have been compiled for the period 1993-1999. ${ }^{47}$ While the SSRIs caused between 1-3 deaths/million prescriptions, venlafaxine had an index of over 13 deaths/million prescriptions. A subsequent analysis for the period 1998-2000 found similar results (1-3 and 13 deaths/million prescriptions, for SSRIs and venlafaxine, respectively). ${ }^{48}$

Milnacipran appears not to cause any particular concern in overdose. Patients have absorbed up to $2.8 \mathrm{~g}$ (one month's supply at the recommended dose) without any major effects other than sedation. In particular, no cardiovascular complications have been recorded. No fatalities have been recorded with milnacipran alone. ${ }^{49}$ At the present time, no cases of lethal overdose with duloxetine have been published.

\section{Efficacy of milnacipran in preventing recurrent depressive episodes}

Major depression is generally a recurrent disorder and $75 \%-80 \%$ of patients experience repeated episodes..$^{50}$ There is also evidence that the risk of recurrence tends to increase with each successive episode. ${ }^{50,51}$ The role of an efficient antidepressant is therefore not only to get patients well, but to keep them well.

A recurrence prevention study with milnacipran consisted of a six-week open treatment period followed by a continuation phase of 18 weeks for the responders. Patients with a sustained remission at the end of this 24 -week period were randomized to continuing treatment with milnacipran or to placebo under double-blind conditions and followed for a further 12 months. There was significantly less recurrence of depressive episodes in milnacipran-treated patients, as determined by Kaplan-Meier analysis of the cumulative probability of recurrence..$^{52}$ By the end of the 12-month doubleblind phase, $16.3 \%$ of patients treated with milnacipran had relapsed compared with $23.6 \%$ of patients on placebo $(P<0.05)$. The level of tolerability and safety of milnacipran during this 18-month study was equivalent to that reported in relapse/recurrence prevention studies with SSRIs. ${ }^{53,54}$

\section{Milnacipran: a unique antidepressant?}

Whether or not the profile described above justify referring to milnacipran as a unique antidepressant, it is clear that this agent has a distinct combination of characteristics.

It is the only SNRI with a balanced (1:1) activity on NE and 5-HT reuptake inhibition. Its efficacy in mild, moderate, and severe depression and a good overall tolerability are combined with a low risk of causing pharmacokinetic drug-drug interactions, sexual dysfunction, minimal effects on body weight in normal-weight patients, and a lack of toxicity in overdose. This particular profile qualifies milnacipran as a first-line antidepressant for many depressed patients. Milnacipran may be particularly well-suited for low-energy, slowed-down patients. Patients who have been withdrawn from SSRIs or other antidepressants due to lack of efficacy or intolerance may find milnacipran to be an effective therapeutic option.

Note that this overview highlights what we consider to be the most interesting and relevant points of the profile of milnacipran and does not claim to be exhaustive. Approved indications and safety recommendations may vary between countries, so prescribers should check on the summary of product characteristics in their own country.

\section{Disclosure}

Dr Kasper has received grant/research support from Eli Lilly, Lundbeck, Bristol-Myers Squibb, GlaxoSmithKline, Organon, Sepracor and Servier; has served as a consultant or on advisory boards for AstraZeneca, BristolMyers Squibb, GlaxoSmithKline, Eli Lilly, Lundbeck, Pfizer, Organon, Schwabe, Sepracor, Servier, Janssen, and Novartis; and has served on speakers' bureaus for AstraZeneca, Eli Lily, Lundbeck, Schwabe, Sepracor, Servier, Pierre Fabre, and Janssen.

\section{References}

1. Bauer M, Bschor T, Pfennig A, et al. World Federation of Societies of Biological Psychiatry (WFSBP) Guidelines for Biological Treatment of Unipolar Depressive Disorders in Primary Care. World J Biol Psychiatry. 2007;8(2):67-104.

2. Nutt DJ. Relationship of neurotransmitters to the symptoms of major depressive disorder. J Clin Psychiatry. 2008;69 Suppl E1:4-7.

3. Gillman PK. Tricyclic antidepressant pharmacology and therapeutic drug interactions updated. Br J Pharmacol. 2007;151(6):737-748. 
4. Kasper S, Zohar J, Stein DJ, editors. Decision-Making in Psychopharmacology. London: Martin Dunitz; 2002.

5. Koenig AM, Thase ME. First-line pharmacotherapies for depression - what is the best choice? Pol Arch Med Wewn. 2009;119(7-8): 478-486.

6. Moret C, Charveron M, Finberg JP, et al. Biochemical profile of midalcipran (F 2207), 1-phenyl-1-diethyl-aminocarbonyl-2aminomethyl-cyclopropane (Z) hydrochloride, a potential fourth generation antidepressant drug. Neuropharmacology. 1985;24:1211-1219.

7. Moret C, Isaac M, Briley M. Problems associated with long-term treatment with selective serotonin reuptake inhibitors. $J$ Psychopharmacol. 2009;23:967-974.

8. Arroll B, Macgillivray S, Ogston S, et al. Efficacy and tolerability of tricyclic antidepressants and SSRIs compared with placebo for treatment of depression in primary care: A meta-analysis. Ann Fam Med. 2005;3(5):449-456.

9. Anderson IM. Selective serotonin reuptake inhibitors versus tricyclic antidepressants: A meta-analysis of efficacy and tolerability. $J$ Affect Disord. 2000;58(1):19-36.

10. Nutt D, Demyttenaere K, Janka Z, et al. The other face of depression, reduced positive affect: The role of catecholamines in causation and cure. J Psychopharmacol. 2007;21(5):461-471.

11. Stahl SM, Grady MM, Moret C, Briley M. SNRIs: Their pharmacology, clinical efficacy, and tolerability in comparison with other classes of antidepressants. CNS Spectr. 2005;10(9):732-747.

12. Vaishnavi SN, Nemeroff CB, Plott SJ, et al. Milnacipran: A comparative analysis of human monoamine uptake and transporter binding affinity. Biol Psychiatry. 2004;55(3):320-322.

13. Mongeau R, Weiss M, de Montigny C, Blier P. Effect of acute, shortand long-term milnacipran administration on rat locus coeruleus noradrenergic and dorsal raphe serotonergic neurons. Neuropharmacology. 1998;37:905-918.

14. Muneoka K, Shirayama Y, Takigawa M, Shioda S. Brain region-specific effects of short-term treatment with duloxetine, venlafaxine, milnacipran and sertraline on monoamine metabolism in rats. Neurochem Res. 2009;34:542-555.

15. Puozzo C, Leonard BE. Pharmacokinetics of milnacipran in comparison with other antidepressants. Int Clin Psychopharmacol. 1996;11 Suppl 4: $15-27$.

16. Division of Clinical Pharmacology, School of Medicine, Indiana University Schhol of Medicine. P450 Drug Interaction Table. Available from: http://medicine.iupui.edu/clinpharm/ddis/table.asp Accessed on May 25, 2010.

17. Paris BL, Ogilvie BW, Scheinkoenig JA, et al. In vitro inhibition and induction of human liver cytochrome p450 enzymes by milnacipran. Drug Metab Dispos. 2009;37(10):2045-2054.

18. Rosen RC, Lane RM, Menza M. Effects of SSRIs on sexual function: A critical review. J Clin Psychopharmacol. 1999;19:67-85.

19. Keltner NL, McAfee KM, Taylor CL. Mechanisms and treatments of SSRI-induced sexual dysfunction. Perspect Psychiatr Care. 2002;38: $111-116$.

20. Clayton AH, Pradko JF, Croft HA, et al. Prevalence of sexual dysfunction among newer antidepressants. J Clin Psychiatry. 2002;63: $357-366$.

21. Raskin J, Goldstein DJ, Mallinckrodt CH, Ferguson MB. Duloxetine in the long-term treatment of major depressive disorder. J Clin Psychiatry. 2003;64:1237-1244.

22. Detke MJ, Wiltse CG, Mallinckrodt CH, et al. Duloxetine in the acute and long-term treatment of major depressive disorder: A placeboand paroxetine-controlled trial. Eur Neuropsychopharmacol. 2004; 14:457-470.

23. Baldwin D, Moreno RA, Briley M. Resolution of sexual dysfunction during acute treatment of major depression with milnacipran. Hum Psychopharmacol. 2008;23(6):527-532.

24. Michelson D, Fava M, Amsterdam J, et al. Interruption of selective serotonin reuptake inhibitor treatment. Double-blind, placebo-controlled trial. Br J Psychiatry. 2000;176:363-368.
25. Pinzani V, Ginies E, Robert L, et al. Venlafaxine withdrawal syndrome: Report of six cases and review of the literature. Rev Med Interne. 2000;21(3):282-284.

26. Perahia DG, Kajdasz DK, Desaiah D, Haddad PM. Symptoms following abrupt discontinuation of duloxetine treatment in patients with major depressive disorder. J Affect Disord. 2005;89(1-3):207-212.

27. Vandel P, Sechter D, Weiller, et al. Post-treatment emergent adverse events in depressed patients following treatment with milnacipran and paroxetine. Hum Psychopharmacol. 2004;19(8):585-586.

28. Ness-Abramof R, Apovian CM. Drug-induced weight gain. Drugs Today (Barc). 2005;41:547-555.

29. Pierre Fabre Médicament - data on file.

30. Kasper S, Pletan Y, Solles A, Tournoux A. Comparative studies with milnacipran and tricyclic antidepressants in the treatment of patients with major depression: A summary of clinical trial results. Int Clin Psychopharmacol. 1996;11 Suppl 4:35-39.

31. Lopez-Ibor J, Guelfi JD, Pletan Y, et al. Milnacipran and selective serotonin reuptake inhibitors in major depression. Int Clin Psychopharmacol. 1996;11 Suppl 4:41-46.

32. Sechter D, Vandel P, Weiller E, et al. A comparative study of milnacipran and paroxetine in outpatients with major depression. J Affect Disord. 2004;83(2-3):233-236.

33. Clerc G; Milnacipran/Fluvoxamine Study Group. Antidepressant efficacy and tolerability of milnacipran, a dual serotonin and noradrenaline reuptake inhibitor: A comparison with fluvoxamine. Int Clin Psychopharmacol. 2001;16(3):145-151.

34. Montes JM, Ferrando L, Saiz-Ruiz J. Remission in major depression with two antidepressant mechanisms: Results from a naturalistic study. $J$ Affect Disord. 2004;79(1-3):229-234.

35. Li GY, Ueki H, Yamamoto Y, Yamada S. Association between the scores on the general health questionnaire-28 and the saliva levels of 3-methoxy-4-hydroxyphenylglycol in normal volunteers. Biol Psychol. 2006;73(2):209-211.

36. Ferguson JM, Mendels J, Schwart GE. Effects of reboxetine on Hamilton Depression Rating Scale factors from randomized, placebo-controlled trials in major depression. Int Clin Psychopharmacol. 2002;17(2):45-51.

37. Papakostas GI, Fava M. A meta-analysis of clinical trials comparing milnacipran, a serotonin-norepinephrine reuptake inhibitor, with a selective serotonin reuptake inhibitor for the treatment of major depressive disorder. Eur Neuropsychopharmacol. 2007;17(1):32-36.

38. Ansseau M, Papart P, Troisfontaines B, et al. Controlled comparison of milnacipran and fluoxetine in major depression. Psychopharmacology (Berl). 1994;114(1):131-137.

39. Ansseau M, von Frenckell R, Gérard MA, et al. Interest of a loading dose of milnacipran in endogenous depressive inpatients. Comparison with the standard regimen and with fluvoxamine. Eur Neuropsychopharmacol. 1991;1(2):113-121.

40. Guelfi JD, Ansseau M, Corruble E, et al. A double-blind comparison of the efficacy and safety of milnacipran and fluoxetine in depressed inpatients. Int Clin Psychopharmacol. 1998;13(3):121-128.

41. Lee MS, Ham BJ, Kee BS, et al. Comparison of efficacy and safety of milnacipran and fluoxetine in Korean patients with major depression. Curr Med Res Opin. 2005;21(9):1369-1375.

42. Montgomery SA, Baldwin DS, Blier P, et al. Which antidepressants have demonstrated superior efficacy? A review of the evidence. Int Clin Psychopharmacol. 2007;22(6):323-329.

43. Mansuy L. Antidepressant therapy with milnacipran and venlafaxine. Neuropsychiatric Disease Treatment. 2010 (this supplement).

44. Papakostas GI, Thase ME, Fava M, et al. Are antidepressant drugs that combine serotonergic and noradrenergic mechanisms of action more effective than the selective serotonin reuptake inhibitors in treating major depressive disorder? A meta-analysis of studies of newer agents. Biol Psychiatry. 2007;62(11):1217-1227.

45. Settle EC Jr. Antidepressant drugs: Disturbing and potentially dangerous adverse effects. J Clin Psychiatry. 1998;59 Suppl 16:25-30.

46. Mazur JE, Doty JD, Krygiel AS. Fatality related to a 30 -g venlafaxine overdose. Pharmacotherapy. 2003;23(12):1668-1672. 
47. Buckley NA, McManus PR. Fatal toxicity of serotoninergic and other antidepressant drugs: Analysis of United Kingdom mortality data. BMJ. 2002;325(7376):1332-1333.

48. Cheeta S, Schifano F, Oyefeso A, et al. Antidepressant-related deaths and antidepressant prescriptions in England and Wales, 1998-2000. Br J Psychiatry. 2004;184:41-47.

49. Montgomery SA, Prost JF, Solles A, Briley M. Efficacy and tolerability of milnacipran: An overview. Int Clin Psychopharmacol. 1996;11 Suppl 4: 47-51.

50. Angst J. Course of mood disorders: A challenge to psychopharmacology. Clin Neuropharmacol. 1992;15 Suppl (1 Pt A):444-445.

51. Maj M, Veltro F, Pirozzi R, et al. Pattern of recurrence of illness after recovery from an episode of major depression: A prospective study. Am J Psychiatry. 1992;149(6):795-800.
52. Rouillon F, Warner B, Pezous N, et al. Milnacipran efficacy in the prevention of recurrent depression: A 12-month placebo-controlled study. Int Clin Psychopharmacol. 2000;15(3):133-140.

53. Doogan DP, Caillard V. Sertraline in the prevention of depression. Br J Psychiatry. 1992;160:217-222.

54. Montgomery SA, Dunbar G. Paroxetine is better than placebo in relapse prevention and the prophylaxis of recurrent depression. Int Clin Psychopharmacol. 1993;8(3):189-195.

55. Koch S, Hemrick-Luecke SK, Thompson LK, et al. Comparison of effects of dual transporter inhibitors on monoamine transporters and extracellular levels in rats. Neuropharmacology. 2003;45(7):935-944.

56. Deecher DC, Beyer CE, Johnston G, et al. Desvenlafaxine succinate: A new serotonin and norepinephrine reuptake inhibitor. J Pharmacol Exp Ther. 2006;318(2):657-665.

\section{Publish your work in this journal}

Neuropsychiatric Disease and Treatment is an international, peerreviewed journal of clinical therapeutics and pharmacology focusing on concise rapid reporting of clinical or pre-clinical studies on a range of neuropsychiatric and neurological disorders. This journal is indexed on PubMed Central, the 'PsycINFO' database and CAS, and is the official

Submit your manuscript here: http://www.dovepress.com/neuropsychiatric-disease-and-treatment-journal journal of The International Neuropsychiatric Association (INA). The manuscript management system is completely online and includes a very quick and fair peer-review system, which is all easy to use. Visit http://www.dovepress.com/testimonials.php to read real quotes from published authors. 